\title{
Communication \\ An LC Wireless Passive Pressure Sensor Based on Single-Crystal MgO MEMS Processing Technique for High Temperature Applications
}

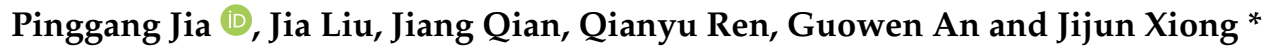 \\ Science and Technology on Electronic Test and Measurement Laboratory, North University of China, \\ Taiyuan 030051, China; pgjia@cqu.edu.cn (P.J.); jialiu@nuc.edu.cn (J.L.); b1806019@st.nuc.edu.cn (J.Q.); \\ b1806005@st.nuc.edu.cn (Q.R.); anguowen@nuc.edu.cn (G.A.) \\ * Correspondence: xiongjijun@nuc.edu.cn
}

Citation: Jia, P.; Liu, J.; Qian, J.; Ren, Q.; An, G.; Xiong, J. An LC Wireless Passive Pressure Sensor Based on Single-Crystal MgO MEMS Processing Technique for High Temperature Applications. Sensors 2021, 21, 6602. https://doi.org/ $10.3390 / \mathrm{s} 21196602$

Academic Editor: Faisal Mohd-Yasin

Received: 10 August 2021

Accepted: 1 October 2021

Published: 3 October 2021

Publisher's Note: MDPI stays neutral with regard to jurisdictional claims in published maps and institutional affiliations.

Copyright: (c) 2021 by the authors. Licensee MDPI, Basel, Switzerland. This article is an open access article distributed under the terms and conditions of the Creative Commons Attribution (CC BY) license (https:/ / creativecommons.org/licenses/by/ $4.0 /)$.
Abstract: An LC wireless passive pressure sensor based on a single-crystalline magnesium oxide $(\mathrm{MgO}) \mathrm{MEMS}$ processing technique is proposed and experimentally demonstrated for applications in environmental conditions of $900^{\circ} \mathrm{C}$. Compared to other high-temperature resistant materials, $\mathrm{MgO}$ was selected as the sensor substrate material for the first time in the field of wireless passive sensing because of its ultra-high melting point $\left(2800^{\circ} \mathrm{C}\right)$ and excellent mechanical properties at elevated temperatures. The sensor mainly consists of inductance coils and an embedded sealed cavity. The cavity length decreases with the applied pressure, leading to a monotonic variation in the resonant frequency of the sensor, which can be retrieved wirelessly via a readout antenna. The capacitor cavity was fabricated using a MgO MEMS technique. This MEMS processing technique, including the wet chemical etching and direct bonding process, can improve the operating temperature of the sensor. The experimental results indicate that the proposed sensor can stably operate at an ambient environment of $22-900^{\circ} \mathrm{C}$ and $0-700 \mathrm{kPa}$, and the pressure sensitivity of this sensor at room temperature is $14.52 \mathrm{kHz} / \mathrm{kPa}$. In addition, the sensor with a simple fabrication process shows high potential for practical engineering applications in harsh environments.

Keywords: LC wireless passive; high temperature; pressure sensor; single-crystal MgO; wet etching; direct bonding

\section{Introduction}

High-temperature pressure measurements play an important role in many applications, such as turbine engines, high-speed aircraft, nuclear power plants, and other aerospace applications [1-4]. To date, various types of sensing devices have been developed for monitoring pressure in high-temperature environments by using different sensing mechanisms and sensitive materials, including piezoelectric pressure sensors $\left(\mathrm{LiNbO}_{3}, \mathrm{Ca}_{2} \mathrm{Al}_{2} \mathrm{SiO}_{7}\right.$, and $\left.\mathrm{YCOB}\right)[5-7]$, piezoresistive pressure sensors (silicon-on-insulator, $\mathrm{SiC}$, and poly-Si) [8-10], optical fiber pressure sensors (silica fiber and photonic crystal fiber) [11,12], and wireless passive pressure sensors (alumina and zirconia ceramics) [13-15].

Wireless passive inductive capacitive (LC) resonance sensors are good candidates in high-temperature or rotation environments because of their lower operating frequency, simple manufacturing, and near-field coupling distance [16]. So far, single and multiparameter wireless passive sensors based on a low- and high-temperature co-fired ceramics (LTCC)/(HTCC) technique have been reported [17-23]. Tan et. al proposed an LC wireless passive sensor based on LTCC, an imidization process, and screen-printing technology for simultaneous multi-parameter sensing, and demonstrated that the sensor can work in an ambient environment of $25-200{ }^{\circ} \mathrm{C}, 24-90 \% \mathrm{RH}$, and $70-220 \mathrm{kPa}$, with a pressure sensitivity value of $3.25 \mathrm{kHz} / \mathrm{kPa}$ [24]. Lin et. al presented a wireless passive pressure and temperature-integrated LC resonant sensor, which adopted the low Young's modulus 
materials as the sensor substrate. The pressure sensitivity is $1.16 \mathrm{kHz} / \mathrm{kPa}$ within the measurement range of $140-850 \mathrm{kPa}$ at $500{ }^{\circ} \mathrm{C}$ [25]. However, compared to ceramics, singlecrystal materials are more suitable for high-temperature sensors in long-term practical applications due to their stable physical and chemical properties. In our previous work, an LC-type pressure sensor based on sapphire was reported, but the pressure sensitivity was $10 \mathrm{kHz} / \mathrm{kPa}$ and the operating temperature was only $600{ }^{\circ} \mathrm{C}$ [26].

Single-crystalline magnesium oxide $(\mathrm{MgO})$ is an attractive composition material for high-temperature sensors because of its superior mechanical, low dielectric constant, low high-frequency dielectric loss, ultra-high melting point $\left(2800^{\circ} \mathrm{C}\right)$, and thermal properties at elevated temperatures $[27,28]$. In this paper, we propose a single-crystal MgO MEMS-based LC wireless passive pressure sensor for harsh monitoring. The sensor consists of a variable capacitance, an inductance, and a vacuum-sealed cavity. First, a wet chemical etching method was used to fabricate a cylindrical cavity structure on the $\mathrm{MgO}$ surface. Then, direct bonding of the etched $\mathrm{MgO}$ and bare $\mathrm{MgO}$ was performed to obtain a sealed cavity as the sensor substrate. Finally, the wireless coupling test was performed on a high-temperature, high-pressure experiment platform to verify the sensor performance. In addition, the thermal stress mismatch within the sensor structure was reduced by developing the MEMS technology of $\mathrm{MgO}$. This sensor can be batch-produced and is expected to be used in ultra-high-temperature environments.

\section{Sensor Design and Principle}

The equivalent circuit schematic of the sensing system is illustrated in Figure 1a. The planar inductance coils and reader antenna of the resonant sensor are coupled when the reader antenna is close to the sensor. The sensor is resonant when the frequency of the sweep signal is the same as the self-resonance frequency of the sensor. Afterwards, the input impedance and phase of the reader antenna changes with the external environment. The sensor resonant frequency can be obtained by tracking and extracting the change in the resonance information of the reader antenna, and can be expressed as [29]

$$
f_{0}=\frac{1}{2 \pi \sqrt{L_{p} C_{p}}}
$$

where $L_{p}$ and $C_{p}$ are the constant inductance and variable capacitor of the sensor, respectively.

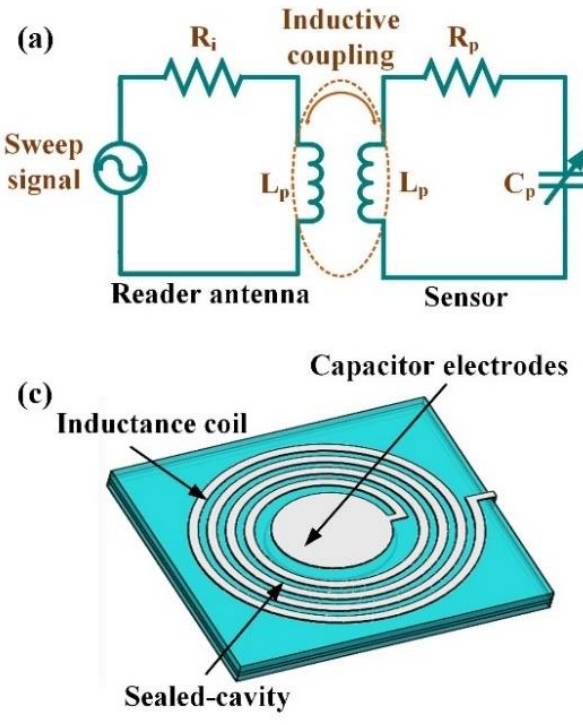

(b)
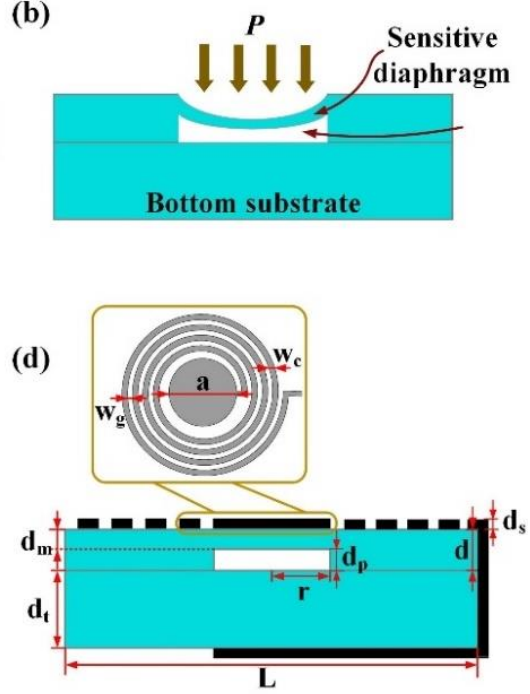

Figure 1. Schematic diagram of sensor operation. (a) Illustrative equivalent circuit schematic model of LC measurement. (b) Pressure sensing principle. (c) Structure of the sensor. (d) 3D model of the sensor. 
As for the pressure loading, the formula for calculating the resonant capacitor $C_{p}$ can be expressed as [30]

$$
\begin{aligned}
& C_{p}(P)=\frac{C_{p}(0)}{\sqrt{\frac{\varepsilon_{r} d_{0}}{\varepsilon_{r} d_{p}}}}+\tan ^{-1} \sqrt{\frac{\varepsilon_{r} d_{0}}{\varepsilon_{r} d_{p}}} \\
& C_{p}(0)=\frac{\varepsilon_{0} d}{d_{p}}+\frac{\varepsilon_{r} \varepsilon_{0}\left(L^{2}-4 d^{2}\right)}{d_{p}}
\end{aligned}
$$

where $d_{p}$ is the depth of the pressure cavity, $d_{m}$ is the thickness of the pressure diaphragm, $L$ is the side-length of the substrate, $\varepsilon_{r}$ and $\varepsilon_{0}$ are the relative permittivity of the substrate dielectric and vacuum permittivity, respectively, and $\varepsilon_{0}=9.65 \times 10^{-12} \mathrm{~F} / \mathrm{m}$.

As shown in Figure 1b, when external pressure is applied to the diaphragm, the maximum deformation occurs in the center of the diaphragm. The center deflection $d_{0}$ of the sensitive diaphragm with the applied pressure can be expressed as [31]

$$
d_{0}=\frac{3\left(1-\mu^{2}\right) P}{16 E d_{m}^{3}}(r)^{4}
$$

where $r$ is the radius of the cavity, $P$ is the pressure applied on the diaphragm, $E$ is Young's modulus, and $\mu$ is Poisson's ratio. For MgO, $E=256.6 \mathrm{GPa}$ and $\mu=0.157$. Furthermore, the maximum deformation of the diaphragm and the pressure measurement range are restrained by the structure parameters of the sensor. Therefore, the desired pressure sensitivity and measurement range can be obtained by adjusting the radius of the cavity and the thickness of the sensitive diaphragm.

Figure 1c shows the 3D model of the sensor, which consists of an embedded sealed cavity, inductance coils, and capacitance electrodes. The cross-section schematic diagram of the sensor is shown in Figure 1d; the overall structure of the sensor is a square with a side length of $20 \mathrm{~mm}$ and a height of $0.6 \mathrm{~mm}$. The mechanical deformation and output response frequency of the sensor can be optimized through numerical simulation and electromagnetic simulation. Considering the performance, size, and coupling distance of the sensors, the sensor parameters are shown in Table 1.

Table 1. Geometrical parameters of the designed LC wireless passive sensor.

\begin{tabular}{lll}
\hline Parameter & Symbol & Value (mm) \\
\hline Thickness of the sensitive diaphragm & $\mathrm{d}_{\mathrm{m}}$ & 0.124 \\
Thickness of the support layer & $\mathrm{d}_{\mathrm{t}}$ & 0.4 \\
Length of the cavity & $\mathrm{d}_{\mathrm{p}}$ & 0.076 \\
Length of the sensor substrate & $\mathrm{L}$ & 20 \\
Radius of the cavity & $\mathrm{r}$ & 4 \\
Diameter of the capacitor & $\mathrm{a}$ & 8 \\
Width of inductance coils & $\mathrm{w}_{\mathrm{c}}$ & 0.5 \\
Space of inductance coils & $\mathrm{w}_{\mathrm{g}}$ & 0.5 \\
Thickness of the coils & $\mathrm{d}_{\mathrm{s}}$ & 0.02 \\
\hline
\end{tabular}

\section{Sensor Fabrication}

The fabrication process of the LC wireless passive pressure sensor mainly consists of three steps: wet chemical etching, direct bonding, and screen-printing, as shown in Figure 2. $\mathrm{MgO}\{100\}$ with a side length of $20 \mathrm{~mm}$ and thicknesses of $400 \mu \mathrm{m}$ and $200 \mu \mathrm{m}$ were selected as the bottom substrate and sensitive diaphragm layer, respectively. 


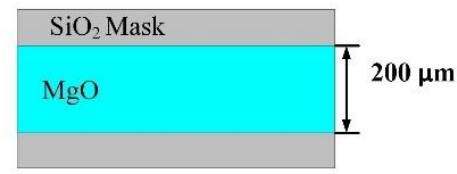

(a) PECVD deposit $1 \mu \mathrm{m}$ of $\mathrm{SiO}_{2}$

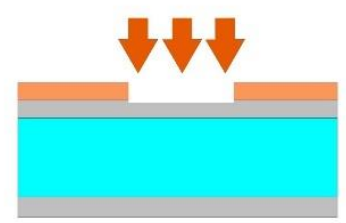

(b) A circular shape transferred to the $\mathrm{SiO}_{2}$ film by photolithography process

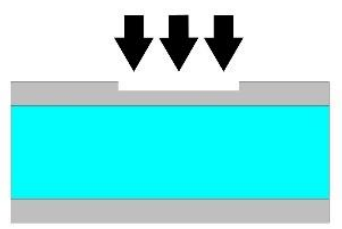

(c) $\mathrm{RIE}$ remove $\mathrm{SiO}_{2}$

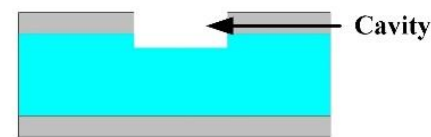

(d) A cavity etched by phosphoric acid

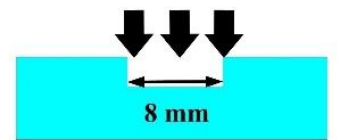

(e) $\mathrm{RIE}$ remove $\mathrm{SiO}_{2}$

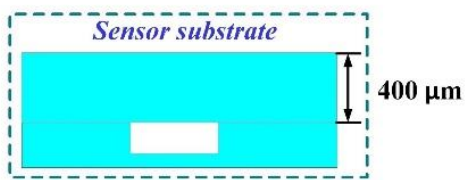

(f) Direct bonding

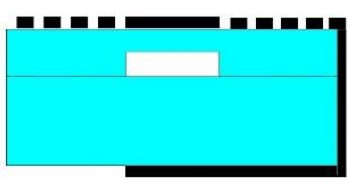

(g) Screen printing

Figure 2. The fabrication process of the single-crystal MgO LC wireless passive pressure sensor.

First, a cylindrical deep cavity was fabricated on $\mathrm{MgO}$ (thickness of $200 \mu \mathrm{m}$ ) by using the wet chemical etching method, as shown in Figure $2 \mathrm{a}-\mathrm{e}$. In our previous work, we analyzed the effect of different etchants on the surface morphology, surface roughness, and surface elements of $\mathrm{MgO}$ [32]. Phosphoric acid is the preferred etchant and the etching parameters are a concentration of $50 \%$ and a temperature of $120{ }^{\circ} \mathrm{C}$. After a duration of $17 \mathrm{~min}$, a cylindrical cavity with a diameter of $8 \mathrm{~mm}$ and a depth of approximately $74 \mu \mathrm{m}$ (in theory) was obtained. Correspondingly, the thickness of the pressure-sensitive diaphragm was $126 \mu \mathrm{m}$. Then, direct bonding of the etched $\mathrm{MgO}$ and bare $\mathrm{MgO}$ (thickness of $400 \mu \mathrm{m}$ ) was performed, using a surface activation-assisted high-temperature annealing direct bonding method, as shown in Figure $2 \mathrm{f}$. According to our previous research on the bonding strength of $\mathrm{MgO} / \mathrm{MgO}$ under different annealing conditions [33], the parameters of direct bonding for the sensor substrate were determined to be a pressure of $4 \mathrm{MPa}$, a temperature of $1300{ }^{\circ} \mathrm{C}$, and a duration of $140 \mathrm{~min}$. Then, the vacuum-sealed cavity was produced.

To evaluate the etching and bonding quality, the cavity and bonding interface were observed by a scanning electron microscope (SEM, SU5000, HITACHI, Tokyo, Japan), as illustrated in Figure 3. The cross-sectional SEM image shown in Figure 3a indicates that the cavity length is $76.1 \mu \mathrm{m}$, which is consistent with the theoretical calculation. From Figure $3 b-d$, it can be seen that the cavity is complete, and the bonding interface is smooth and void-free, which contributes to the sealing of the pressure capacitor cavity.

Finally, a high melting point metal platinum electronic paste (Pt) (ESL5541-A, ESL Ltd., King of Prussia, PA, USA) was used to print inductance coils. Capacitor electrodes and inductor coils were printed on both sides of the sensor substrate with Pt paste by a screen printing technique. Specifically, the bonded $\mathrm{MgO}$ sample was aligned and pasted to the printing screen and the $\mathrm{Pt}$ was printed onto the $\mathrm{MgO}$ surface. The silk-screen had the geometrical parameters of a thickness of $25 \mu \mathrm{m}$ and a resolution of approximately 320 meshes. After screen printing, the bonded structure was introduced into a muffle furnace to adhere the $\mathrm{Pt}$ layer to the sensor substrate. Figure $4 \mathrm{a}$ shows the sintering curve of the Pt conductor. The sensor fabrication was accomplished after the above processes, and the images of the fabricated sensor are shown in Figure $4 b, c$. The enlarged images of the inductance coils observed by optical microscope are shown in Figure 4 d,e. It can be seen that the edge of the inductance coil is clear and complete. At the same time, the SEM 
results, shown in Figure $4 \mathrm{f}, \mathrm{g}$, demonstrate that there was no change in the microstructure of the Pt before and after the high-temperature pressure test.

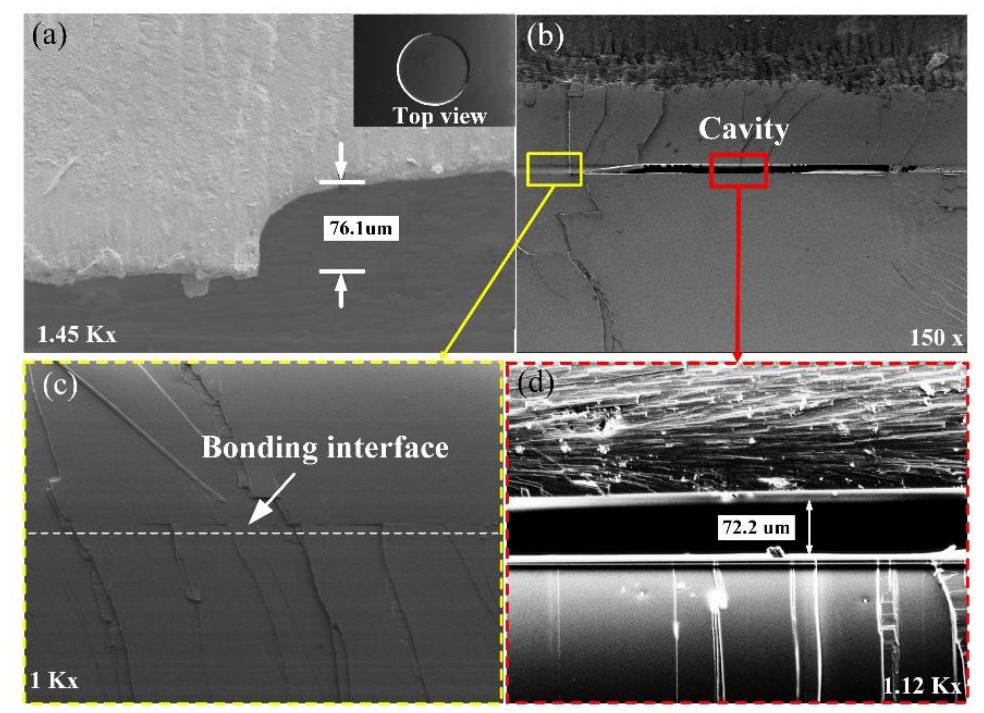

Figure 3. (a) The cross-selection SEM image of the cavity. (b-d) SEM images of the bonding interface and cavity at different magnifications.
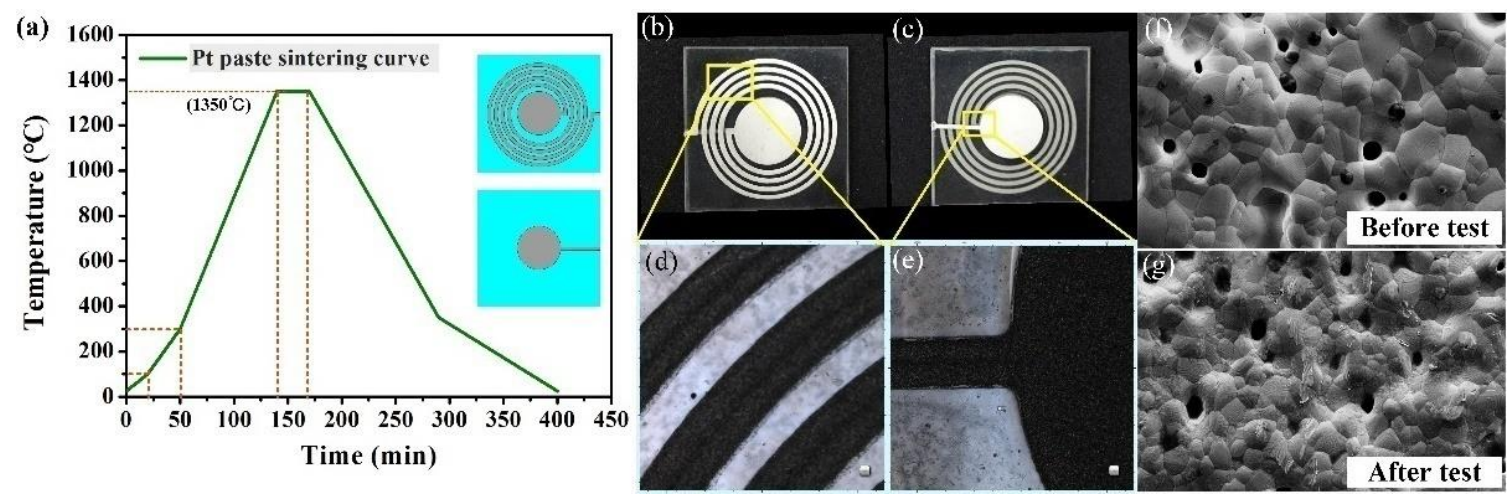

Figure 4. (a) Sintering curve of Pt conductor. $(\mathbf{b}, \mathbf{c})$ The top and bottom layers of the sensor. (d,e) The partially enlarged details of the inductors. (f,g) SEM images of Pt before and after high-temperature pressure testing.

\section{Experiments and Results}

A high-temperature and pressure composite measurement platform (JT-300, Chengdu Jiangtai Co., Ltd., Chengdu, China) was used to verify the feasibility and performance of the wireless passive pressure sensor, as shown in Figure 5. The sensor was placed on the ceramic tray with a hole, which ensured that the temperature and pressure were accurately applied to the sensor. A copper reading antenna was placed at a vertical distance of $2 \mathrm{~mm}$ from the sensor, and the other end of the reader was connected to a network analyzer via a cable for gathering the resonance frequency, which is suitable for wireless sensing applications in small, confined spaces and high-temperature mechanical rotating structures. In addition, the cable can be immune to high-temperature damage by being placed above the insulation mullite. The temperature (accuracy of $0.5^{\circ} \mathrm{C}$ ) in the tank was controlled by the electric control cabinet and displayed in real time. Below the tank was a $\mathrm{N}_{2}$ entrance, and the pressure with the accuracy of $0.01 \mathrm{kPa}$ applied to the sensor was controlled by adjusting the amount of $\mathrm{N}_{2}$. 

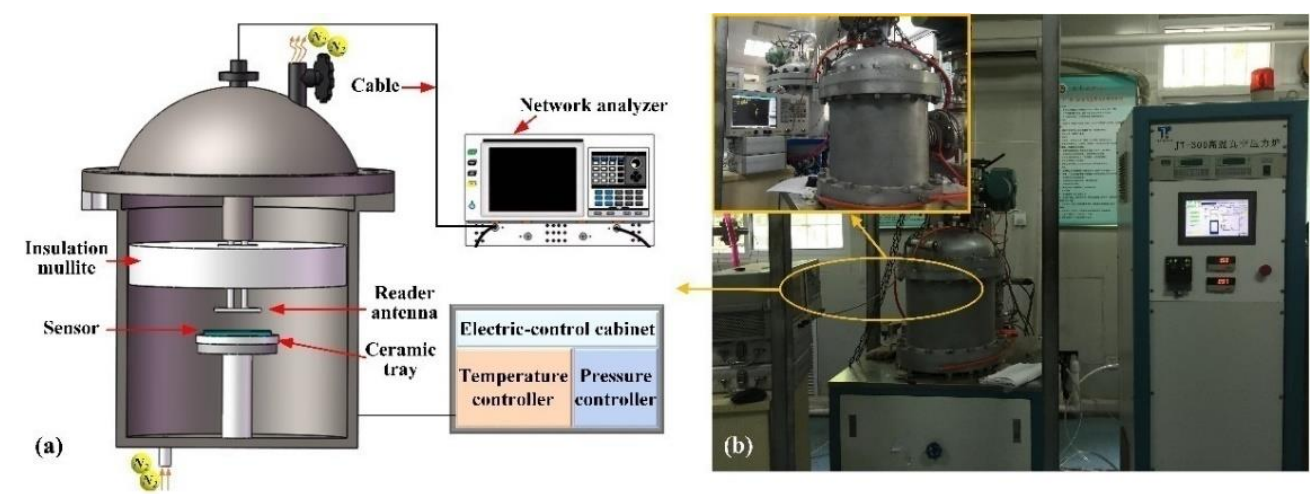

Figure 5. Temperature-pressure composite measurement platform. (a) Working principle of pressure measurement system. (b) High-temperature pressure experimental platform.

First, we increased the pressure from approximately $0 \mathrm{kPa}$ to $700 \mathrm{kPa}$ at intervals of $100 \mathrm{kPa}$ at room temperature to verify the resonant frequency responses to pressure. The results shown in Figure 6a indicate that the frequency of the sensor decreased from $116.672 \mathrm{MHz}$ to $106.509 \mathrm{MHz}$ due to the sealed-cavity deformation during the pressure loading process, and the pressure sensor realized a high sensitivity of $14.52 \mathrm{kHz} / \mathrm{kPa}$ at room temperature. Furthermore, we also investigated the resonant frequency as a function of the pressure increasing and decreasing at room temperature to illustrate the hysteresis and repeatability of the sensor. As can be seen from Figure 6b, the coincidence of the frequency curves from the three experiments proves that the sensor has a repeatable response, and the resonant frequency is approximately linear with the pressure. Moreover, the hysteresis error is about $0.94 \%$ from the first increasing and decreasing pressure experiment.
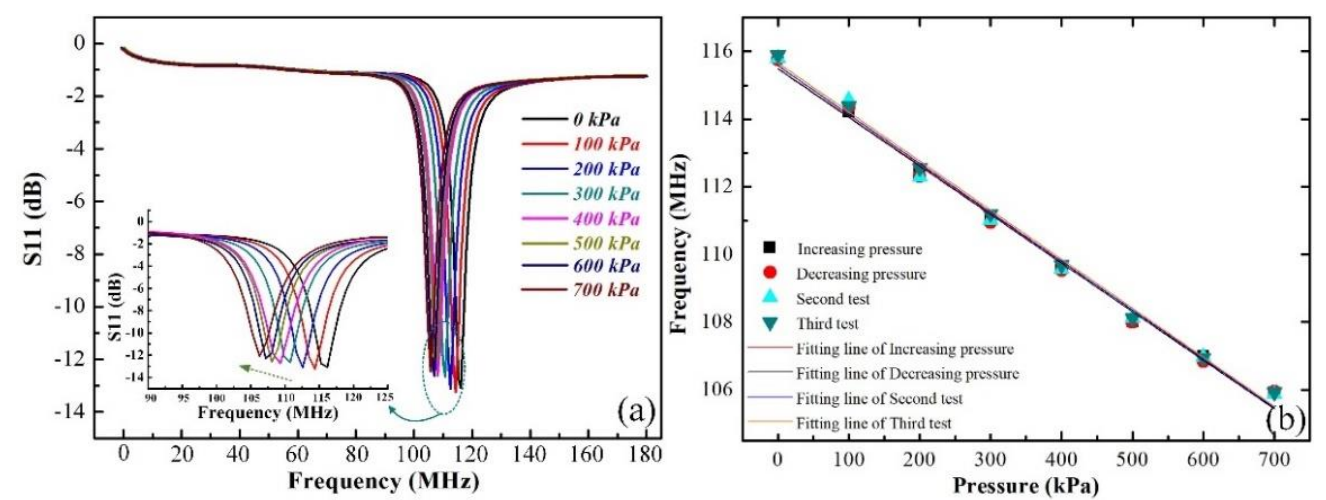

Figure 6. Pressure test results of the proposed sensor at room temperature. (a) The pressure versus resonant frequency curve under $0 \mathrm{kPa}-700 \mathrm{kPa}$. (b) The frequency responses to pressure during the pressure increasing and decreasing process.

Next, we increased the temperature from $22^{\circ} \mathrm{C}$ to $900{ }^{\circ} \mathrm{C}$ at intervals of $100{ }^{\circ} \mathrm{C}$ under a pressure of approximately $0 \mathrm{kPa}$. The relationship between the amplitude of $\mathrm{S} 11$ and the temperature is shown in Figure 7a. Since the temperature was increased, some of the electrons were excited by the thermal stimulus and left the external electric field. Thermal excitation causes electrons to move irregularly, which increases the impedance of the inductor and reduces the current generated by the electric field. Therefore, the amplitude of S11 gradually attenuates with the increasing temperature. Although the signal intensity at $900{ }^{\circ} \mathrm{C}$ is much weaker than at room temperature, the resonant frequency of the sensor can still be extracted. The result shown in Figure $7 \mathrm{~b}$ indicates that the initial frequency of the sensor shifted uniformly toward a low frequency, and the frequency drift was $3.015 \mathrm{kHz} /{ }^{\circ} \mathrm{C}$. Figure $7 \mathrm{c}$ shows the resonant frequency responses to the pressure (from approximately $0 \mathrm{kPa}$ to $700 \mathrm{kPa}$ ) at $900{ }^{\circ} \mathrm{C}$. The resonant frequency decreased 
from $113.201 \mathrm{MHz}$ to $101.491 \mathrm{MHz}$, and the pressure sensitivity of the sensor changed to $16.72 \mathrm{kHz} / \mathrm{kPa}$. Figure $7 \mathrm{~d}$ shows the maximum error of frequency at different pressures in a $900{ }^{\circ} \mathrm{C}$ environment and demonstrates that the sensor is reasonable and reliable.
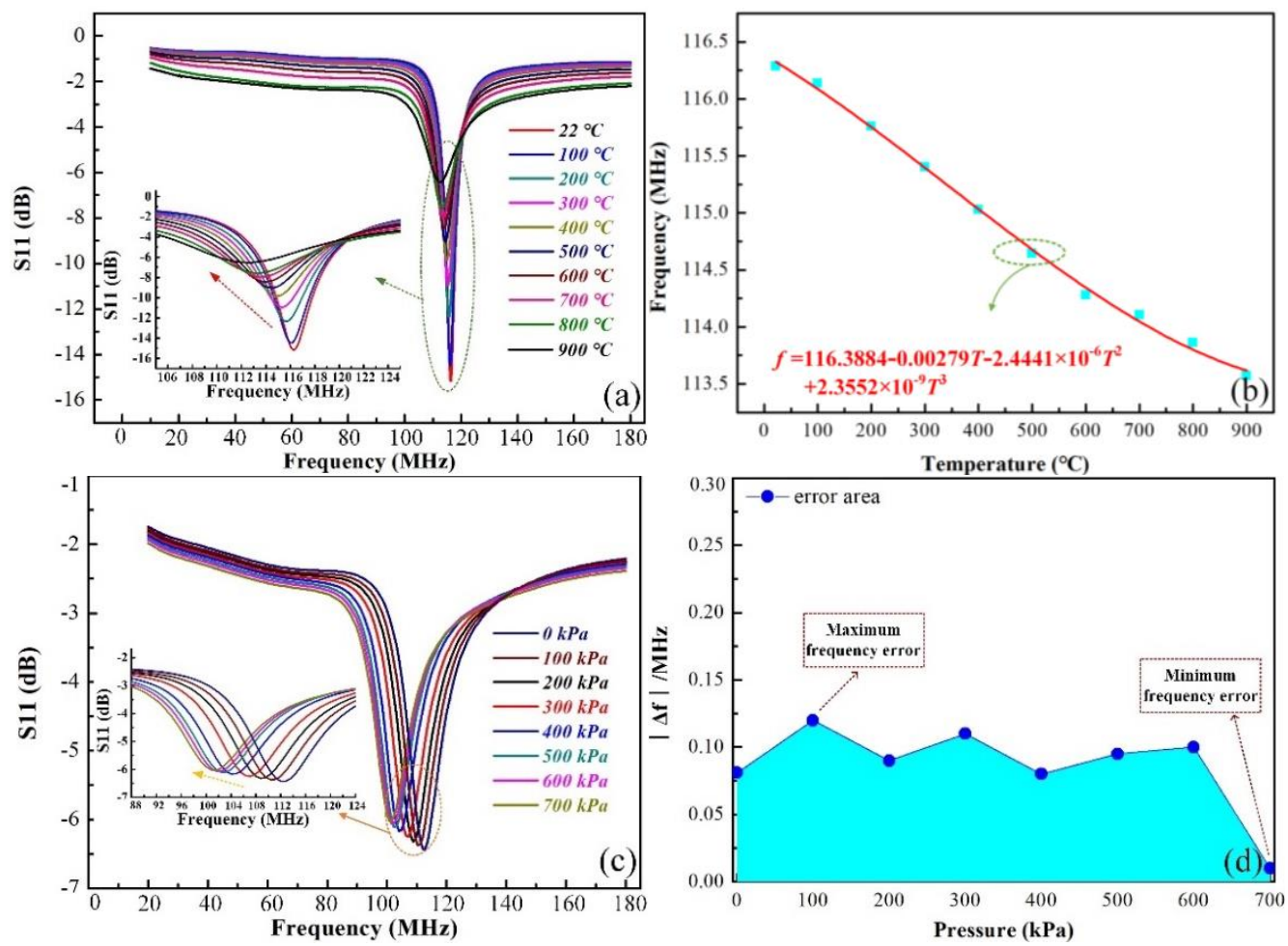

Figure 7. (a) The resonant frequency changes with the temperature under $0 \mathrm{kPa}$. (b) The zero drift of the sensor. (c) The pressure versus frequency from $0 \mathrm{kPa}$ to $700 \mathrm{kPa}$ at $900{ }^{\circ} \mathrm{C}$. (d) The frequency error of the sensor at $900{ }^{\circ} \mathrm{C}$.

Further, the resonant frequency varied with the pressure of the sensor at different temperatures (from $22{ }^{\circ} \mathrm{C}$ to $900{ }^{\circ} \mathrm{C}$, increment of $100{ }^{\circ} \mathrm{C}$ ), as shown in Figure 8a. It can be seen that the resonant frequency changed linearly with the pressure within the range of $20 \mathrm{kPa}$ to $700 \mathrm{kPa}$. The pressure sensitivity of the sensor was between $22^{\circ} \mathrm{C}$ and $900{ }^{\circ} \mathrm{C}$ and is displayed in Figure $8 \mathrm{~b}$. It can be seen that the pressure sensitivity increased with the temperature. This was mainly due to the high temperature affecting the elastic modulus, the thermal expansion coefficient, and the dielectric constant of $\mathrm{MgO}$. In addition, a wireless temperature sensor can be integrated with the pressure sensor for calibrating the pressure frequency drift.
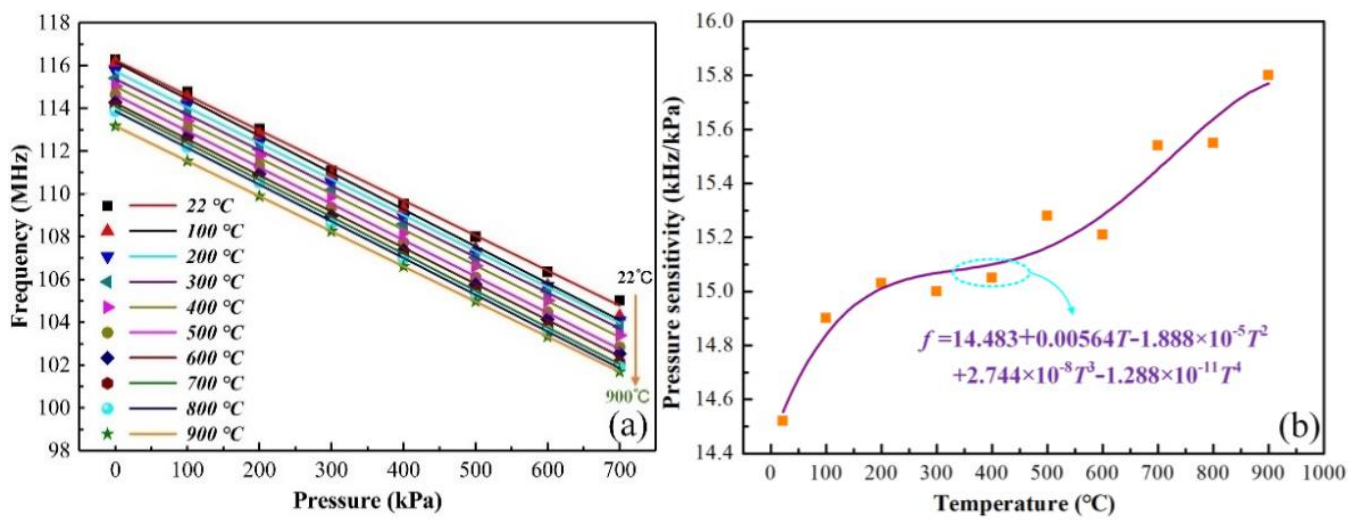

Figure 8. (a) The pressure versus resonant frequency curve at temperatures of $22-900{ }^{\circ} \mathrm{C}$. (b) The pressure sensitivity of the sensor at different temperatures. 


\section{Conclusions}

In this work, an LC wireless passive pressure sensor based on a single-crystalline magnesium oxide (MgO) MEMS processing technique was proposed and experimentally demonstrated for applications in high-temperature environments up to $900{ }^{\circ} \mathrm{C}$. The capacitor cavity was fabricated using a MgO MEMS technique. This MEMS processing technique, including the wet chemical etching and direct bonding process, can improve the operating temperature of the sensor. The experimental results show that the resonant frequency changed linearly with the pressure. With the temperature change from $22^{\circ} \mathrm{C}$ to $900{ }^{\circ} \mathrm{C}$, the pressure sensitivity of the sensor increased from $14.52 \mathrm{kHz} / \mathrm{kPa}$ to $16.72 \mathrm{kHz} / \mathrm{kPa}$. This paper provides a batch-production and integrated manufacturing method of the pressure sensor for high-temperature applications, which helps to ensure the consistency of sensors, improve the production efficiency, and reduce costs. We think using single-crystal materials is one of the development trends for high-temperature sensors in the future.

Author Contributions: Conceptualization, P.J. and J.L.; methodology, P.J.; software J.L.; validation, Q.R.; formal analysis, J.L.; investigation, G.A.; resources, J.Q.; data curation, J.Q.; writing-original draft preparation, P.J. and J.L.; writing—review and editing, J.X.; visualization, J.X.; supervision, J.X.; project administration, P.J. and J.X.; funding acquisition, J.X. All authors have read and agreed to the published version of the manuscript.

Funding: This work was supported by the National Natural Science Foundation of China under grant numbers 51935011 and 52075505, the Innovative Research Group Project of National Science Foundation of China under grant number 51821003.

Institutional Review Board Statement: Not applicable.

Data Availability Statement: Not applicable.

Conflicts of Interest: The authors declare no conflict of interest.

\section{References}

1. Habib, Z.; Parthasarathy, R.; Gollahalli, S. Performance and emission characteristics of biofuel in a small-scale gas turbine engine. Appl. Energy 2009, 87, 1701-1709. [CrossRef]

2. Kang, J.S.; Yang, S.S. Fast-response total pressure probe fore turbomachinery application. Journal of Mechanical Science and Technology. J. Mech. Sci. Technol. 2010, 24, 569-574. [CrossRef]

3. Wilson, W.C.; Atkinson, G.M. Passive Wireless Sensor Applications for NASA's Extreme Aeronautical Environments. IEEE Sens. J. 2014, 14, 3745-3753. [CrossRef]

4. Fonseca, M.; English, J.; Von Arx, M.; Allen, M. Wireless micromachined ceramic pressure sensor for high-temperature applications. J. Microelectromechanical Syst. 2002, 11, 337-343. [CrossRef]

5. Zhang, X.; Wang, F.-Y.; Li, L. Optimal selection of piezoelectric substrates and crystal cuts for SAW-based pressure and temperature sensors. IEEE Trans. Ultrason. Ferroelectr. Freq. Control. 2007, 54, 1207-1216. [CrossRef]

6. Takeda, H.; Hagiwara, M.; Noguchi, H.; Hoshina, T.; Takahashi, T.; Kodama, N.; Tsurumi, T. Calcium aluminate silicate Ca2Al2SiO7 single crystal applicable to piezoelectric sensors at high temperature. Appl. Phys. Lett. 2013, 102, 242907. [CrossRef]

7. Kim, K.; Zhang, S.; Salazar, G.; Jiang, X. Design, fabrication and characterization of high temperature piezoelectric vibration sensor using YCOB crystals. Sens. Actuators A: Phys. 2012, 178, 40-48. [CrossRef]

8. Ngo, H.-D.; Mukhopadhyay, B.; Ehrmann, O.; Lang, K.-D. Advanced Liquid-Free, Piezoresistive, SOI-Based Pressure Sensors for Measurements in Harsh Environments. Sensors 2015, 15, 20305-20315. [CrossRef] [PubMed]

9. Okojie, R.S.; Lukco, D.; Nguyen, V.; Savrun, E. $4 \mathrm{H}-\mathrm{SiC}$ piezoresistive pressure sensors at $800{ }^{\circ} \mathrm{C}$ with observed sensitivity recovery. IEEE Electron. Device Lett. 2015, 36, 174-176. [CrossRef]

10. Li, X.; Liu, Q.; Pang, S.; Xu, K.; Tang, H.; Sun, C. High-temperature piezoresistive pressure sensor based on implantation of oxygen into silicon wafer. Sens. Actuators A: Phys. 2012, 179, 277-282. [CrossRef]

11. Zhang, Y.; Yuan, L.; Lan, X.; Kaur, A.; Huang, J.; Xiao, H. High-temperature fiber-optic Fabry-Perot interferometric pressure sensor fabricated by femtosecond laser. Opt. Lett. 2013, 38, 4609-4612. [CrossRef]

12. Yi, J.; Lally, E.; Wang, A.; Xu, Y. Demonstration of an All-Sapphire Fabry-Pérot Cavity for Pressure Sensing. IEEE Photon- Technol. Lett. 2010, 23. [CrossRef]

13. Sturesson, P.; Khaji, Z.; Knaust, S.; Klintberg, L.; Thornell, G. Thermomechanical properties and performance of ceramic resonators for wireless pressure reading at high temperatures. J. Micromech. Microeng. 2015, 25, 095016. [CrossRef]

14. Huang, Q.-A.; Dong, L.; Wang, L.-F. LC Passive Wireless Sensors Toward a Wireless Sensing Platform: Status, Prospects, and Challenges. J. Microelectromechanical Syst. 2016, 25, 822-841. [CrossRef] 
15. Nopper, R.; Has, R.; Reindl, L. A wireless sensor readout systemcircuit concept, simulation, and accuracy. IEEE Trans. Instrum. Meas. 2011, 60, 2976-2983. [CrossRef]

16. Li, C.; Tan, Q.; Jia, P.; Zhang, W.; Liu, J.; Xue, C.; Xiong, J. Review of Research Status and Development Trends of Wireless Passive LC Resonant Sensors for Harsh Environments. Sensors 2015, 15, 13097-13109. [CrossRef] [PubMed]

17. Nowak, D.; Dziedzic, A. LTCC package for high temperature applications. Microelectron. Reliab. 2011, 51, 1241-1244. [CrossRef]

18. Ma, M.; Khan, H.; Shan, W.; Wang, Y.; Ou, J.Z.; Liu, Z.; Kalantar-Zadeh, K.; Li, Y. A novel wireless gas sensor based on LTCC technology. Sens. Actuators B: Chem. 2017, 239, 711-717. [CrossRef]

19. Qin, L.; Shen, D.; Wei, T.; Tan, Q.; Luo, T.; Zhou, Z.; Xiong, J. A Wireless Passive LC Resonant Sensor Based on LTCC under High-Temperature/Pressure Environments. Sensors 2015, 15, 16729-16739. [CrossRef]

20. Tan, Q.; Wei, T.; Chen, X.; Luo, T.; Wu, G.; Li, C.; Xiong, J. Antenna-resonator integrated wireless passive temperature sensor based on low-temperature co-fired ceramic for harsh environment. Sens. Actuators A: Phys. 2015, 236, 299-308. [CrossRef]

21. Gao, R.; Hong, Y.; Zhang, H.; Liu, W.; Liang, T.; Zhang, W.; Xiong, J. A Wireless Pressure Microsensor Fabricated in HTCC Technology for Dynamic Pressure Monitoring in Harsh Environments. Int. J. Distrib. Sens. Netw. 2015, 11. [CrossRef]

22. Radosavljevic, G.J.; Zivanov, L.D.; Smetana, W.; Maric, A.M.; Unger, M.; Nad, L.F. A Wireless Embedded Resonant Pressure Sensor Fabricated in the Standard LTCC Technology. IEEE Sens. J. 2009, 9, 1956-1962. [CrossRef]

23. Ji, Y.; Tan, Q.; Wang, H.; Lv, W.; Dong, H.; Xiong, J. A Novel Surface LCLC Wireless Passive Temperature Sensor Applied in Ultra-High Temperature Measurement. IEEE Sens. J. 2018, 19, 105-112. [CrossRef]

24. Tan, Q.; Lv, W.; Ji, Y.; Song, R.; Lu, F.; Dong, H.; Zhang, W.; Xiong, J. A LC wireless passive temperature-pressure-humidity (TPH) sensor integrated on LTCC ceramic for harsh monitoring. Sens. Actuators B: Chem. 2018, 270, 433-442. [CrossRef]

25. Lin, L.; Ma, M.; Zhang, F.; Liu, F.; Liu, Z.; Li, Y. Integrated passive wireless pressure and temperature dual-parameter sensor based on LTCC technology. Ceram. Int. 2018, 44, S129-S132. [CrossRef]

26. Li, W.; Liang, T.; Liu, W.; Jia, P.; Chen, Y.; Xiong, J.; Lei, C.; Hong, Y.; Li, Y. Wireless passive pressure sensor based on sapphire direct bonding for harsh environments. Sens. Actuators A: Phys. 2018, 280, 406-412. [CrossRef]

27. Gao, D.S.; Gao, X.D.; Wu, Y.Q.; Zhang, T.T.; Yang, J.N.; Li, X.M. Epitaxial codoped BaSnO3 thin films with tunable optical bandgap on $\mathrm{MgO}$ substrate. Appl. Phys. A Mater. Sci. Process 2019, 125, 158. [CrossRef]

28. Choge, D.K.; Chen, H.X.; Guo, L.; Li, G.W.; Liang, W.G. Double-pass high-efficiency sumfrequency generation of a broadband orange laser in a single MgO: PPLN crystal. Opt. Mater. Express 2019, 9, 837-844. [CrossRef]

29. Wu, S.-Y.; Hung, C.-Y.; Hsu, W. A wirelessly readable and resettable shock recorder through the integration of LC circuits and MEMS devices. Smart Mater. Struct. 2014, 23. [CrossRef]

30. Li, C.; Tan, Q.; Xiong, J.; Jia, P.; Hong, Y.; Ren, Z.; Luo, T.; Liu, J.; Xue, C.; Zhang, W. A noncontact wireless passive radio frequency (RF) resonant pressure sensor with optimized design for applications in high-temperature environments. Meas. Sci. Technol. 2014, 25. [CrossRef]

31. Giovanni, M. Flat and Corrugated Diaphragm Design Handbook; Mercel Dekker: New York, NY, USA, 1982.

32. Liu, J.; Jia, P.; Chen, X.; Liang, T.; Liu, H.; Liu, W.; Xiong, J.; Jia, P. Surface characterization of patterning on MgO single crystals using wet chemical etching process to advance MEMS devices. J. Micromechanics Microengineering 2019, 30, 015001. [CrossRef]

33. Liu, J.; Jia, P.; Li, J.; Feng, F.; Liang, T.; Liu, W.; Xiong, J. Hydrophilic Direct Bonding of MgO/MgO for High-Temperature MEMS Devices. IEEE Access 2020, 8, 67242-67249. [CrossRef] 